\title{
Oral Health of Korean Patients With Head and Neck Cancer
}

\author{
Young-Seok Kim ${ }^{1}$, Yun-Sook Jung ${ }^{2}$, Bo-Kyoung Kim ${ }^{3}$, Eun-Kyong Kim ${ }^{1}$
}

${ }^{1}$ Department of Dental Hygiene, College of Science \& Technology, Kyungpook National University, Sangju, ${ }^{2}$ Department of Preventive Dentistry, School of Dentistry, Kyungpook National University, Daegu, ${ }^{3}$ Department of Dental Science, Yonsei University Graduate School, Seoul, Korea

\begin{abstract}
Background: Association between periodontitis and of head and neck carcinoma was suggested. In the present study, we evaluated the oral health status of patients with head and neck carcinoma and analyzed the relationship between cancer characteristics and oral health. Methods: Oral health of 40 patients with head and neck carcinoma was examined. Decayed teeth, missing teeth, plaque index, gingival index, and probing depth were measured. Cancer type and site were recorded based on the patients' medical records.

Results: The average age of participants was $60.10 \pm 8.99$ years, and 35 of participants were male. The decay or missing teeth index was $5.43 \pm 5.57$, and the plaque index, gingival index, and probing depth were $1.37 \pm 1.03,1.57 \pm 0.84$, and $4.13 \pm 1.45$, respectively. These indexes showed no significant difference according to the type or site of cancer $(P>0.05)$.

Conclusions: This study showed that there was no correlation between oral health parameters and characteristics of head and neck carcinoma. (J Cancer Prev 2018;23:77-81)
\end{abstract}

Key Words: Oral health, Head and neck cancer, Periodontal diseases

\section{INTRODUCTION}

Cancers of the head and neck (HNC) constitute a heterogenous group of malignancies of varied sites above the clavicle, such as lips, tongue, tonsil, oral cavity, salivary gland, pharynx, and larynx. ${ }^{1}$ Although the frequency of $\mathrm{HNC}$ is about $2 \%$ of all types of cancers, the incidence of HNC has steadily increased for both men and women in Korea since $1998{ }^{2} \mathrm{HNC}$ is of great interest because of its potentially destructive consequences with regard to the patients' quality of life. ${ }^{3}$ Alcohol consumption and cigarette smoking are established risk factors for HNC originating from the oral cavity, pharynx, and larynx. ${ }^{4.5}$

In general, most patients with HNC are habitual users of tobacco and alcohol. Recently, human papillomaviruses have been shown to play an important role in carcinogenesis, especially in HNC, including cancers of the tonsils, base of the tongue, and other parts of the pharynx. ${ }^{6,7}$ In addition, Tezal et $a{ }^{8}{ }^{8}$ reported that severity of periodontitis was associated with increased risk of head and neck squamous cell carcinoma (HNSCC).

Periodontal disease is a chronic and destructive disease associated with dental plaque that progresses slowly and is the major cause of tooth loss in adults. ${ }^{9,10}$ Many recent studies have reported a relationship between periodontal disease and risk of systemic disease, such as cardiovascular disease, diabetes mellitus, and premature birth. In addition, several studies have reported that periodontal disease shows the strongest degree of association with oral cancer. ${ }^{11,12}$ However, the reciprocal effects of periodontal disease and cancer are unclear. Abnet et al. ${ }^{13}$ reported that carcinogenic metabolic by-products of periodontal disease are possibly involved in the relationship between periodontal disease and cancer. Under the assumption that biomarkers of inflammation, such as myeloperoxidase and superoxide, are elevated in periodontitis, polymorphisms of related genes were

Received June 9, 2018, Revised June 18, 2018, Accepted June 20, 2018

Correspondence to: Eun-Kyong Kim

Department of Dental Hygiene, College of Science \& Technology, Kyungpook National University, 2559 Gyeongsang-daero, Sangju 37224, Korea

Tel: +82-54-530-1423, Fax: +82-54-530-1429, E-mail: jinha01@naver.com, ORCID: Eun-Kyong Kim, https://orcid.org/0000-0001-9582-1415

Copyright (C) 2018 Korean Society of Cancer Prevention

(c) This is an Open Access article distributed under the terms of the Creative Commons Attribution Non-Commercial License (http://creativecommons.org/icenses/by-nc/4.0) which permits unrestricted non-commercial use, distribution, and reproduction in any medium, provided the original work is properly cited. 
reported to be associated with elevated cancer risk. ${ }^{14}$

However, the association between HNC characteristics and oral health status among patients with HNC has not been evaluated in Korea. Therefore, the purpose of the present study was to evaluate the oral health status of patients with HNC and analyze the relationship between cancer characteristics and oral health status parameters such as tooth decay and periodontal health.

\section{MATERIALS AND METHODS}

\section{Subjects}

Patients who were referred to a dental clinic for oral examination and management before radiation therapy among those diagnosed with HNC at the Yeungnam University Medical Centers' Otolaryngology Department Clinic were screened. Among these, patients with no previous diagnosis of HNC and radiotherapy, without infectious disease, and with good cooperation for oral examination and management were included. Those who were edentulous or refused to participate after receiving information on the purpose and examination procedure of the study were excluded. Finally, 40 patients who were in agreement with the purpose and methods of the present study, and provided informed consent, were selected. Before initiation, the study was approved by the Institutional Review Board of Yeungnam University Hospital (YUH-13-0396-O41).

\section{Methods}

\section{1) Oral examination}

In all patients, oral examinations were performed before radiotherapy on the dental chair. Oral examination procedures were performed by one examiner, and questionnaire survey was conducted by one dental hygienist. Evaluation for decayed teeth (DT) and missing teeth (MT) included all teeth except the third molar. Plaque index (PI), gingival index (GI), and probing depth (PD) were measured on six representative teeth i.e., the maxillary right first molar and central incisor, maxillary left first molar, mandibular left central incisor and left first molar, and mandibular right first molar. PI and GI were measured according to the Löe and Silness criteria, with a higher number indicating more accumulation of plaque or poorer gingival health as follows: PI - 0 (no plaque), 1 (a film of plaque adhering to the free gingival margin and adjacent area of the tooth, which cannot be visualized with the naked eye, but only with use of a disclosing solution or probe), 2 (moderate accumulation of deposits within the gingival pocket, on the gingival margin and/or adjacent tooth surface, which can be visualized with the naked eye), 3 (abundance of soft matter within the gingival pocket and/or on the tooth and gingival margin); and GI-0 (no inflammation), 1 (mild inflammation, slight change in color, slight edema, and no bleeding on probing), 2 (moderate inflammation, moderate glazing, redness, and bleeding on probing), 3 (severe inflammation, marked redness and hypertrophy, ulceration, and tendency to spontaneous bleeding). ${ }^{15}$ The highest value of PI, GI, or PD was considered to be the representative value of each participant, respectively.

\section{2) Systemic health}

Sex, age, general health status, smoking, and drinking status were surveyed using a questionnaire. Characteristics of cancer (site, type) were examined from the patients' medical records. Type of cancer was classified as squamous cell carcinoma (SCC), adenoid cystic carcinoma, pleomorphic adenoma, or others based on the medical records.

\section{Statistical analysis}

Statistical analysis was performed using IBM SPSS for Windows ver. 20.0 (IBM Co., Armonk, NY, USA). Kruskal-Wallis test and Mann-Whitney U-test were performed to compare characteristics of cancer between the dental status groups. $P$-value of $<0.05$ was considered as significant.

\section{RESULTS}

\section{General and cancer characteristics in the participants}

The average age of participants was $60.10 \pm 8.99$ years, and 35 of participants were male. Of the total participants, $47.5 \%$ had a history of systemic disease such as hypertension and diabetes; $52.5 \%$ were smokers; and $57.5 \%$ drank alcohol. Among the participants with $\mathrm{HNC}$, the rate of SCC was $75.0 \%$, rate of adenoid cystic carcinoma was $7.5 \%$, and rate of pleomorphic adenoma was $5.0 \%$. Of the total cancer rate, rate of cancer of the larynx was $27.5 \%$, and rates of other cancers of the nasopharynx, floor of mouth, tonsil, and salivary gland were with lower, in decreasing order (Table 1).

2. Oral status of participants with head and neck according to general and cancer characteristics

The decay or missing teeth (DMT) median (range, min-max) value were 3.5 (0-18), and those of the PI, GI, and PD were 1 (0-3), 2 (0-3), and 4 (2-8), respectively. The DMT, PI, and PD of male 
Table 1. General and cancer characteristics in the participants

\begin{tabular}{lc}
\hline \multicolumn{1}{c}{ Characteristic } & Value \\
\hline Total & $40(100.0)$ \\
Sex & $35(87.5)$ \\
Male & $5(12.5)$ \\
Female & $60.10 \pm 8.99$ \\
Age (yr) & $18(45.0)$ \\
$\quad \leq 59$ & $22(55.0)$ \\
$\geq 60$ & \\
General disease & $21(52.5)$ \\
No & $19(47.5)$ \\
Yes & \\
Smoking & $19(47.5)$ \\
None & $21(52.2)$ \\
Current & $17(42.5)$ \\
Drinking & $23(57.5)$ \\
$\quad$ None & \\
Current & $30(75.0)$ \\
Cancer type & $3(7.5)$ \\
Squamous cell carcinoma & $2(5.0)$ \\
Adenoid cystic carcinoma & $5(12.5)$ \\
Pleomorphic adenoma & \\
Other & $11(27.5)$ \\
Cancer site & $5(12.5)$ \\
Larynx & $3(7.5)$ \\
Nasopharynx & $3(7.5)$ \\
Floor of mouth & $3(7.5)$ \\
Tonsil & $10(25.0)$ \\
Salivary gland & \\
Other & \\
\hline
\end{tabular}

Values are presented as number (\%) or mean \pm standard deviation.

participants were 4 (0-18), 1 (0-3), and 4 (2-8), respectively, which was higher than the corresponding values of female participants, without significance. In addition, there were no statistical differences in oral status according general disease or smoking. MT of participants over 60 years old was 4 (0-17) and of those under 59 years old was $2.5(0-9)$, with significant difference $(P<$ $0.05)$. DT and PD of the current drinker group were statistically higher than those of the non-drinker group $(P<0.05)$. DMT of SCC patients was $5(0-18)$ and that of other cancer participants was 2 (0-9). PI 1.5 (0-3) and PD 4.5 (3-6) of patients with other cancers were slightly higher than those of patients with SCC, without significance. DMT of patients with cancer of the larynx was $12(0-17)$ and those of patients with cancer of the nasopharynx, floor of mouth, tonsil, salivary gland, etc., were of lower value, in order. However, DMT and periodontal status showed no significant difference according to the site of cancer (Table 2).

\section{DISCUSSION}

The aim of the present study was to evaluate the association of the oral status with the HNC characteristics. DT and PD were significantly increased according to the presence of alcohol consumption. Other variables were not significant, but showed a trend toward increase with alcohol consumption, as well as with smoking. Many studies have shown that drinking and smoking are the main causes of development of periodontal disease, which are considered to be confounding variables in the assessment of periodontal status in cancer patients. ${ }^{16.17}$

To our knowledge, no study has focused on the differences in oral status according to the type and location of cancer in Korea. In our study, there was no significant difference between periodontal disease and tooth disease according to cancer site or cancer type. Many previous studies have reported that most patients with HNC have more MT than those of the general population, even after adjusting for smoking or drinking status. ${ }^{16.18,19}$ Proinflammatory proteins and bacterial toxins are related to the development of periodontal disease; hence, it is postulated that these mediators play a role in the etiology of HNC in patients with periodontal disease. ${ }^{20}$ In our study, the results are attributed to the fact that chemical mediators (proinflammatory proteins or bacterial toxins) act on periodontal tissue, irrespective of the type and location of cancer, and cause periodontal disease. Taken together, these results indicate that the periodontal status depends on the inflammatory action of the cancer itself rather than the location or type of cancer.

In addition, there was no significant difference in DT or DMT (tooth disease parameters) according to location or type of cancer. A previous study reported the potential mechanisms by which cariogenic bacteria such as Mutans streptococci may protect the host from cancer $^{21}$; however, no conclusion could be made with regard to the anti-cancer effect of cariogenic bacteria due to limitations of the study design and suggestion of a putative mechanism without bacterial examination. ${ }^{22}$ Therefore, further research on the relationship between mechanism of cancer and dental caries is required.

Our study has some limitations. First, analysis was without adjusting for confounding variables of drinking and smoking. In addition, the subjects were few and the oral status was not compared to that of a healthy control group. In future studies, it is expected that improvement to overcome these limitations will provide more meaningful results. Nevertheless, this was the first study to explore the association between oral health status and characteristics of HNC in patients in Korea. Collaboration 
Table 2. Oral status of participants with head and neck according to general and cancer characteristics

\begin{tabular}{|c|c|c|c|c|c|c|}
\hline Variable & DT & MT & DMT & PI & GI & PD \\
\hline Total $(\mathrm{n}=40)$ & $0(0-7)$ & $3(0-17)$ & $3.5(0-18)$ & $1(0-3)$ & $2(0-3)$ & $4(2-8)$ \\
\hline \multicolumn{7}{|l|}{ Sex } \\
\hline Male $(\mathrm{n}=35)$ & $0(0-7)$ & $3(0-17)$ & $4(0-18)$ & $1(0-3)$ & $2(0-3)$ & $4(2-8)$ \\
\hline Female $(\mathrm{n}=5)$ & $0(0-2)$ & $2(0-8)$ & $2(0-8)$ & $1(0-3)$ & $2(0-3)$ & $4(3-6)$ \\
\hline \multicolumn{7}{|l|}{ Age (yr) } \\
\hline$\leq 59(\mathrm{n}=18)$ & $0(0-7)$ & $2.5(0-9)^{\mathrm{a}}$ & $3(0-9)$ & $1(0-3)$ & $2(0-2)$ & $3.5(2-7)$ \\
\hline$\geq 60(\mathrm{n}=22)$ & $0(0-5)$ & $4(0-17)^{a}$ & $4.5(0-18)$ & $2(0-3)$ & $2(0-3)$ & $4(2-8)$ \\
\hline \multicolumn{7}{|l|}{ General disease } \\
\hline No $(n=21)$ & $0(0-7)$ & $2(0-15)$ & $4(0-18)$ & $1(0-3)$ & $2(0-2)$ & $33(2-8)$ \\
\hline Yes $(\mathrm{n}=19)$ & $0(0-5)$ & $3(0-17)$ & $3(0-17)$ & $2(0-3)$ & $2(0-3)$ & $4(2-7)$ \\
\hline \multicolumn{7}{|l|}{ Smoking } \\
\hline None $(\mathrm{n}=19)$ & $0(0-3)$ & $1(0-17)$ & $1(0-18)$ & $1(0-3)$ & $2(0-3)$ & $3(3-6)$ \\
\hline Current $(n=21)$ & $0(0-7)$ & $3(0-17)$ & $5(0-17)$ & $1(0-3)$ & $2(0-3)$ & $4(2-8)$ \\
\hline \multicolumn{7}{|l|}{ Drinking } \\
\hline None $(n=17)$ & $0(0-2)^{a}$ & $1(0-17)$ & $1(0-17)$ & $1(0-3)$ & $2(0-3)$ & $3(2-6)^{2}$ \\
\hline Current $(\mathrm{n}=23)$ & $1(0-7)^{a}$ & $3(0-17)$ & $5(0-18)$ & $2(0-3)$ & $2(0-2)$ & $4(3-8)^{2}$ \\
\hline \multicolumn{7}{|l|}{ Cancer type } \\
\hline $\operatorname{SCC}(\mathrm{n}=30)$ & $0(0-6)$ & $3(0-17)$ & $5(0-18)$ & $1(0-3)$ & $2(0-3)$ & $4(2-8)$ \\
\hline Others $(\mathrm{n}=10)$ & $0(0-7)$ & $1.5(0-8)$ & $2(0-9)$ & $1.5(0-3)$ & $1.5(0-3)$ & $4.5(3-6)$ \\
\hline \multicolumn{7}{|l|}{ Cancer site } \\
\hline Larynx $(\mathrm{n}=11)$ & $0(0-6)$ & $7(0-17)$ & $12(0-17)$ & $2(0-3)$ & $2(0-3)$ & $4(3-7)$ \\
\hline Nasopharynx $(\mathrm{n}=5)$ & $0(0-3)$ & $8(0-15)$ & $8(0-18)$ & $1(0-3)$ & $2(0-3)$ & $3(2-6)$ \\
\hline Floor of mouth $(\mathrm{n}=3)$ & $0(0-0)$ & $5(2-9)$ & $5(2-9)$ & $0(0-3)$ & $2(2-2)$ & $3(2-7)$ \\
\hline Tonsil $(\mathrm{n}=3)$ & $2(0-5)$ & $2(1-3)$ & $5(1-7)$ & $1(0-3)$ & $0(0-2)$ & $3(3-7)$ \\
\hline Saliva gland $(\mathrm{n}=3)$ & $0(0-7)$ & $0(0-2)$ & $0(0-9)$ & $1(0-2)$ & $1(0-2)$ & $4(3-5)$ \\
\hline Etc. $(\mathrm{n}=10)$ & $0(0-1)$ & $2.5(0-7)$ & $2.5(0-8)$ & $1(0-3)$ & $5(0-2)$ & $4(3-8)$ \\
\hline
\end{tabular}

Values are presented as median (range). Total results for each variable may be different due to missing values. DT, decayed teeth; MT, missing teeth; DMT, decay or missing teeth; PI, plaque index; GI, gingival index; PD, probing depth; SCC, squamous cell carcinoma. ${ }^{\mathrm{a} D a t a}$ indicates statistical significance shown by Mann-Whitney U-test or Kruskal-Wallis test $(P<0.05)$.

between dental and medical teams may promote patients' general and oral health.

There was no correlation between oral health parameters and HNC characteristics. Regardless of the site or type of cancer, effective prevention and management of dental caries and periodontal disease should be implemented.

\section{CONFLICTS OF INTEREST}

No potential conflicts of interest were disclosed.

\section{REFERENCES}

1. Simard EP, Torre LA, Jemal A. International trends in head and neck cancer incidence rates: differences by country, sex and anatomic site. Oral Oncol 2014:50:387-403.

2. Suh JD, Cho JH. Trends in head and neck cancer in South Korea between 1999 and 2012. Clin Exp Otorhinolaryngol 2016;9: 263-9.

3. van Nieuwenhuizen AJ, Buffart LM, Brug J, Leemans $C R$, Verdonck-de Leeuw IM. The association between health related quality of life and survival in patients with head and neck cancer: a systematic review. Oral Oncol 2015:51:1-11.

4. Zuo JJ, Tao ZZ, Chen C, Hu ZW, Xu YX, Zheng AY, et al. Characteristics of cigarette smoking without alcohol consumption and laryngeal cancer: overall and time-risk relation. A meta-analysis of observational studies. Eur Arch Otorhinolaryngol 2017:274:1617-31.

5. Bagnardi V, Rota M, Botteri E, Scotti L, Jenab M, Bellocco R, et al. Alcohol consumption and lung cancer risk in never smokers: a meta-analysis. Ann Oncol 2011;22:2631-9.

6. Stein AP, Saha S, Yu M, Kimple RJ, Lambert PF. Prevalence of human papillomavirus in oropharyngeal squamous cell carcinoma in the United States across time. Chem Res Toxicol 2014;27: 462-9.

7. Argiris A, Karamouzis MV, Raben D, Ferris RL. Head and neck cancer. Lancet 2008:371:1695-709.

8. Tezal M, Sullivan MA, Hyland A, Marshall JR, Stoler D, Reid ME, et al. Chronic periodontitis and the incidence of head and neck squamous cell carcinoma. Cancer Epidemiol Biomarkers Prev 2009;18:2406-12.

9. Takahashi N, Nyvad B. The role of bacteria in the caries process: ecological perspectives. J Dent Res 2011;90:294-303.

10. Gaffen SL, Hajishengallis G. A new inflammatory cytokine on the block: re-thinking periodontal disease and the Th1/Th2 paradigm 
in the context of Th17 cells and IL-17. J Dent Res 2008;87:817-28.

11. Rezende CP, Ramos MB, Daguíla CH, Dedivitis RA, Rapoport A. Oral health changes in with oral and oropharyngeal cancer. Braz J Otorhinolaryngol 2008;74:596-600.

12. Guha N, Boffetta $P$, Wünsch Filho V, Eluf Neto J, Shangina $O$, Zaridze D, et al. Oral health and risk of squamous cell carcinoma of the head and neck and esophagus: results of two multicentric case-control studies. Am J Epidemiol 2007;166:1159-73.

13. Abnet CC, Qiao YL, Mark SD, Dong ZW, Taylor PR, Dawsey SM. Prospective study of tooth loss and incident esophageal and gastric cancers in China. Cancer Causes Control 2001;12:847-54.

14. Wheatley-Price P, Asomaning K, Reid A, Zhai R, Su L, Zhou W, et al. Myeloperoxidase and superoxide dismutase polymorphisms are associated with an increased risk of developing pancreatic adenocarcinoma. Cancer 2008;112:1037-42.

15. Löe $H$. The gingival index, the plaque index and the retention index systems. J Periodontol 1967;38:Suppl:610-6.

16. Zheng TZ, Boyle P, Hu HF, Duan J, Jian PJ, Ma DQ, et al. Dentition, oral hygiene, and risk of oral cancer: a case-control study in Beijing, People's Republic of China. Cancer Causes
Control 1990;1:235-41.

17. Garrote LF, Herrero R, Reyes RM, Vaccarella S, Anta JL, Ferbeye L, et al. Risk factors for cancer of the oral cavity and oro-pharynx in Cuba. Br J Cancer 2001;85:46-54.

18. Talamini R, Vaccarella S, Barbone F, Tavani A, La Vecchia C, Herrero $\mathrm{R}$, et al. Oral hygiene, dentition, sexual habits and risk of oral cancer. Br J Cancer 2000;83:1238-42.

19. Meyer MS, Joshipura K, Giovannucci E, Michaud DS. A review of the relationship between tooth loss, periodontal disease, and cancer. Cancer Causes Control 2008:19:895-907.

20. Javed F, Warnakulasuriya $\mathrm{S}$. Is there a relationship between periodontal disease and oral cancer? a systematic review of currently available evidence. Crit Rev Oncol Hematol 2016;97:197-205.

21. Tezal M, Scannapieco FA, Wactawski-Wende J, Meurman JH, Marshall JR, Rojas IG, et al. Dental caries and head and neck cancers. JAMA Otolaryngol Head Neck Surg 2013;139:1054-60.

22. Epstein JB, Sciubba JJ, Abt E. Evidence base, epidemiology, correlations, and cause and effect: dental caries and head and neck cancer. Oral Surg Oral Med Oral Pathol Oral Radiol 2014;118:1-4. 